УДК 54-483:54-112

\title{
ТЕХНОЛОГИЯ ПОЛУЧЕНИЯ БЕТУЛИНА МЕТОДОМ ТОНКОПЛЕНОЧНОЙ ПАРОФАЗНОЙ ЭКСТРАКЦИИ
}

\author{
() В.В. Жук ${ }^{* 1}$ В.А. Яновский ${ }^{I}$ О.Б. Самбуева ${ }^{1}$, А.А. Бакибаев ${ }^{2}$ \\ ${ }^{1}$ Сибирский фризико-технический институт им. акад. В.Д. Кузнецова \\ Томского государственного университета, пл. Новособорная, 1, Томск, \\ 634050 (Россия), e-mail: vladzhuk1980@gmail.com \\ ${ }^{2}$ Томский национальный исследовательский политехнический университет, \\ пр. Ленина, 30, Томск, 634050 (Россия), e-mail: bakibaev@mail.ru
}

\begin{abstract}
Представлена технология получения и очистки бетулина из бересты березы. Получение бетулина осуществляется методом тонкопленочной парофазной экстракции, позволяющим интенсифицировать экстракцию за счет проведения процесса в тонком слое при орошении слоя бересты конденсатом экстрагента, а также за счет повышенного градиента концентраций экстрактивных веществ в системе экстрагент - береста. В качестве экстрагента используется водно-этанольная смесь. Очистка полученного суммарного экстракта производится путем его перекристаллизации из высококипящих алифатических углеводородов или их смесей. Разработанная технология позволяет получать бетулин, пригодный для дальнейшего использования в органическом синтезе без дополнительной очистки. Согласно предложенной технологии, выход очищенного бетулина чистотой 88,2-98,3\% составляет 91,4 г на 1000 г исходной бересты. Использованная береста может быть использована для дальнейшего извлечения из нее жирных оксикислот.

Ключевые слова: бетулин, экстракция, перекристаллизация.
\end{abstract}

Работа выполнена при поддержке Министерства образования и науки РФ в рамках ФЦП «Научные и научно-педагогические кадры инновачионной России на 2009-2013 годы» (ГК №16.740.12.0729, Соглашение №14.132.21.1791).

\section{Введение}

Внешний слой коры березы - береста является крупнотоннажным отходом большинства лесоперерабатывающих предприятий, не находящим рационального применения в промышленности. В настоящее время основная масса бересты подвергается термической утилизации.

Вместе с тем береста содержит значительное количество легкодоступных ценных соединений, среди которых преобладают пентациклические тритерпеноиды, основным из которых является бетулин, содержание которого в бересте может достигать 35\% [1].

Экстракты, содержащие бетулин, нашли широкое применение в косметологии и фармакологии. Интерес к бетулину и его производным обусловлен, прежде всего, широким спектром биологической активности этих соединений [2]. Доказано, что бетулин и ряд его производных обладают антисептической, антиокси-

Жук Владислав Витальевич - младший научный сотрудник, e-mail: vladzhuk1980@ gmail.com Яновский Вячеслав Александрович - старший научный сотрудник, кандидат химических наук, e-mail: yavatpu@yandex.ru

Самбуева Оюна Борисовна - младший научный сотрудник, e-mail: oyuna12@yandex.ru Бакибаев Абдигали Абдиманапович - заведующий кафедрой физической и аналитической химии, доктор химических наук, професcop, e-mail: bakibaev@mail.ru дантной, противовоспалительной, противоопухолевой, гепатопротекторной и другими видами биологической активности [2-5]. В настоящее время ведутся интенсивные поиски новых антибактериальных и противовирусных препаратов на основе бетулина, в том числе, обладающих анти-ВИЧ-активностью [2, 6, 7].

Очевидно, что подобные исследования диктуют потребность в эффективных соответствующих

\footnotetext{
* Автор, с которым следует вести переписку.
} 
методах получения бетулина, и также в простых способах очистки его от примесей. Большинство известных способов выделения бетулина основаны на методах экстракции бересты различными растворителями [8-10]. При этом получаемый экстракт содержит, как правило, помимо бетулина, значительные количества других соединений, например, лупеол, лупеоловый альдегид, бетулиновый альдегид, пальмитиновую кислоту $[11,12]$ и нуждается в очистке от них.

Ранее нами был предложен эффективный метод экстракции бетулина - тонкопленочная парофазная экстракция [9, 13], позволяющий интенсифицировать экстракцию за счет проведения процесса в тонком слое при орошении слоя бересты конденсатом экстрагента, а также за счет повышенного градиента концентраций экстрактивных веществ в системе экстрагент - береста. Кроме того, нами было показано, что удобным способом очистки бетулина является перекристаллизация его экстрактов из высококипящих алифатических углеводородов [14, 15].

В продолжение этих исследований целью настоящей работы являлась разработка технологии, сочетающей в себе получение бетулина в виде суммарного этанольного экстракта и его последующую очистку перекристаллизацией, позволяющая получить продукт чистотой 88,2-98,3\%, пригодный для дальнейшего использования в органическом синтезе.

\section{Экспериментальная часть}

На рисунке 1 представлена технологическая схема получения бетулина.

В качестве исходного сырья использовали бересту березы, заготовленную в окрестностях г. Томска. Исходное сырье предварительно высушивали до постоянной массы при температуре $105^{\circ} \mathrm{C}$ для удаления воды. Остаточная влажность бересты составляла 1,8\%. Затем высушенную бересту измельчали в ножевой мельнице до частиц размерами 3-5 мм.

Технологию экстракции и очистки бетулина отрабатывали на лабораторной установке. Конструкция экстрактора была предложена нами ранее $[9,13]$ и приведена на рисунке 2.

Экстрактор представляет собой экстракционную колонну из кварцевого стекла с внутренним диаметром 90 мм и высотой 800 мм (1), сверху которой присоединен обратный холодильник (2), а снизу - кубприемник объемом 5 л (3), оснащенный штуцером для ввода острого водяного пара. Куб-приемник обогревается нагревателем (4). Процесс экстракции осуществляется следующим образом: по мере нагрева пары экстрагента проходят сквозь слой измельченной бересты, конденсируются в обратном холодильнике (2) и через вентиль (5) возвращаются в экстракционную колонну. Конденсат орошает измельченную бересту, проходя через ее слой, обогащается экстрактивными веществами и стекает в куб-приемник. Затем экстрагент вновь испаряется и возвращается в экстракционную колонну, а растворенный экстракт выпадает в осадок в виде гранулята. Ход процесса экстракции контролируют по наличию сухого остатка в стекающем конденсате (6) на выходе экстракционной колонны.

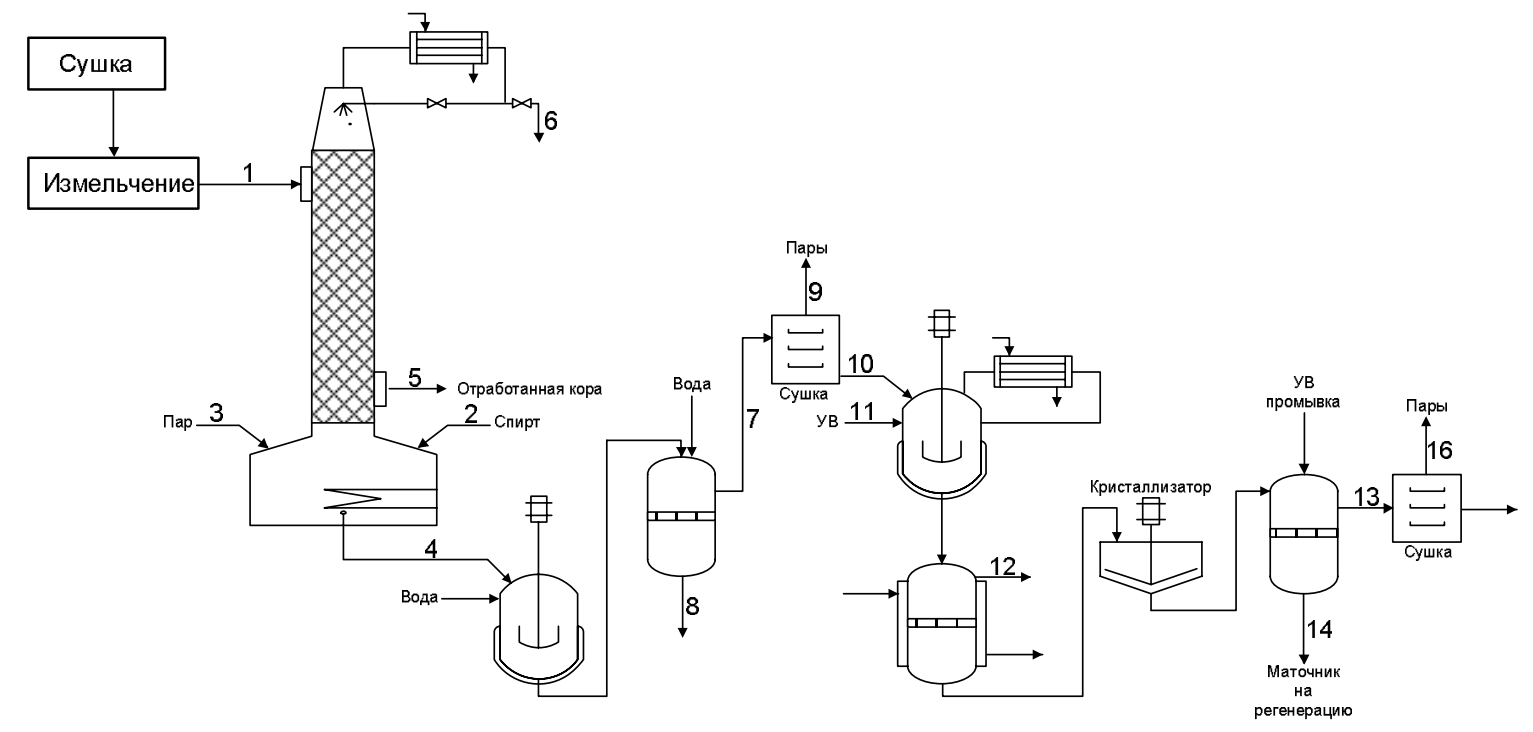

Рис. 1. Технологическая схема процесса получения бетулина 


\section{Рис. 2. Экстрактор}

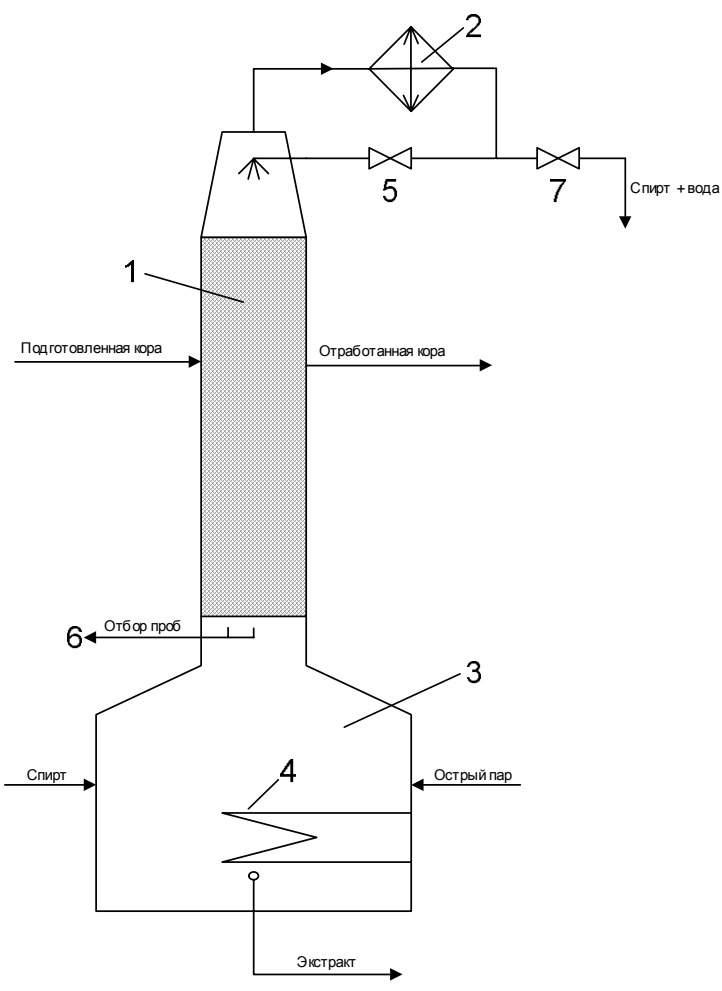

После сушки и измельчения подготовленная береста 1 и спирт-ректификат 2 загружается в экстрактор Э-1, где осуществляется процесс экстракции [9, 13]. В качестве экстрагента использовали 86\%-ный этанол, что обусловлено особенностями ректификации водного раствора спирта. Кроме того, присутствие небольшого количества воды в спирте приводит к увеличению коэффициента извлечения [16]. Продолжительность экстракции составляла 4 ч.

После окончания экстракции маточник 4 направляют на высаживание в емкость E-1, которое осуществляют путем разбавления суммарного экстракта водой. Для удаления спирта из бересты в куб-приемник подают острый водяной пар 3 и отгоняют водно-спиртовую фракцию 6 из бересты в экстракционной колонне для последующей регенерации. Регенерированный спирт используют повторно. Отработанная береста 5 выгружается из колонны и может быть использована для дальнейшего извлечения из нее жирных оксикислот.

После высаживания суспензию направляют на фильтр Ф-1, осадок на фильтре промывают водой, жидкую фазу 8 направляют на регенерацию спирта. Твердый остаток 7 сушат при температуре $105^{\circ} \mathrm{C}$ в сушилке $\mathbf{C - 1 .}$

Затем сухой экстракт 10 подвергают перекристаллизации из декана. Ранее нами было показано, что перекристаллизацию бетулин-содержащих экстрактов удобно проводить в среде высококипящих углеводородных растворителей, таких как нонан или декан, или их смесей $[14,15]$. Кроме того, для удешевления процесса перспективным является применение коммерчески доступных изопарафинов фракции С10-C12 с температурой перегонки 173-193 ${ }^{\circ} \mathrm{C}$, например, нефрас И2-190/320. Согласно технологической схеме, сухой суммарный экстракт 10 загружают в обогреваемую емкость $\mathbf{E - 2}$, растворяют в среде кипящего углеводородного растворителя 11 , полученный раствор подвергают горячему фильтрованию на фильтре Ф-2 для отделения нерастворимых примесей 12. Горячий фильтрат, содержащий бетулин, помещают в кристаллизатор Кр-1 и медленно охлаждают захоложенной водой до температуры 5-10 ${ }^{\circ} \mathrm{C}$. Выпавший в осадок бетулин отделяют фильтрованием на фильтре $\mathbf{\Phi - 3}$ и промывают легкокипящим углеводородным растворителем, например, гептаном. Экономически целесообразным является использование алифатических нефтяных растворителей состава С5-С7, например нефрас П1-65/75 или нефрас С3-94/99. Маточник 14 направляют на регенерацию углеводородов. Твердый остаток после промывки 13 сушат в вакуумной сушилке C-2 при температуре 100-105 ${ }^{\circ} \mathrm{C}$ и получают готовый продукт 15 - бетулин. Пары углеводородов 16 улавливают и направляют на регенерацию.

Материальный баланс, полученный для одного технологического цикла, приведен в таблицах 1-4. 
Таблица 1. Материальный баланс процесса экстракции и отпарки бересты

\begin{tabular}{|c|c|c|c|c|c|}
\hline \multicolumn{3}{|l|}{ Приход } & \multicolumn{3}{|l|}{ Расход } \\
\hline Компонент & Macca, $\Gamma$ & Масс. дол. & Компонент & Macca, $\Gamma$ & Масс. дол. \\
\hline 1. Береста, в т.ч.: & $\underline{1000,0}$ & $\underline{1,000}$ & 5. Отработанная береста, в т.Ч.: & $\underline{1673,9}$ & $\underline{1,000}$ \\
\hline 1.1. Бетулин & 153,0 & 0,153 & 5.1. Бетулин & 24,5 & 0,015 \\
\hline 1.2. Прочие экстрагируемые ве- & & & 5.2. Прочие экстрагируемые ве- & & \\
\hline щества & 43,0 & 0,043 & щества & 6,9 & 0,004 \\
\hline 1.3. Нерастворимая часть & 786,0 & 0,786 & 5.3. Нерастворимая часть & 770,3 & 0,460 \\
\hline 1.4. Вода & 18,0 & 0,018 & 5.4. Спирт & 29,4 & 0,018 \\
\hline & & & 5.5. Вода & 842,8 & 0,503 \\
\hline 2. Спирт-ректификат 86\%, в т.ч.: & $\underline{3000,0}$ & 1,000 & 6. Водно-спиртовая фракция, в т.ч.: & $\underline{1364,2}$ & $\underline{1,000}$ \\
\hline 2.1. Спирт & 2580,0 & 0,860 & 6.1. Спирт & 852,6 & 0,625 \\
\hline 2.2. Вода & 420,0 & 0,140 & 6.2. Вода & 511,6 & 0,375 \\
\hline 3. Пар & 1000,0 & 1,000 & 7. Твердый остаток, в т.Ч.: & $\underline{430,2}$ & $\underline{1,000}$ \\
\hline & & & 7.1. Бетулин & 125,4 & 0,291 \\
\hline & & & 7.2. Прочие экстрагируемые & & \\
\hline & & & вещества & 35,3 & 0,082 \\
\hline & & & 7.3. Спирт & 9,8 & 0,023 \\
\hline & & & 7.4. Вода & 259,7 & 0,604 \\
\hline Вода на высаживание & 2600,0 & 1,000 & 8. Маточник, в т.ч.: & $\underline{4371,8}$ & $\underline{1,000}$ \\
\hline & & & 8.1. Спирт & 1636,6 & 0,374 \\
\hline & & & 8.2. Вода & 2735,2 & 0,626 \\
\hline Вода на промывку & 400,0 & 1,000 & Потери общие & 160,0 & 1,000 \\
\hline Итого: & 8000,0 & & Итого: & 8000 & \\
\hline
\end{tabular}

Таблица 2. Материальный баланс процесса сушки экстракта

\begin{tabular}{|c|c|c|c|c|c|}
\hline \multicolumn{3}{|c|}{ Приход } & \multicolumn{3}{|l|}{ Расход } \\
\hline Компонент & Macca, $\Gamma$ & Масс. дол. & Компонент & Macca, $\Gamma$ & Масс. дол. \\
\hline 7. Твердый остаток, в т.ч.: & $\underline{430,2}$ & $\underline{1,000}$ & 9. Пары, в т.ч.: & $\underline{268,0}$ & $\underline{1,000}$ \\
\hline 7.1. Бетулин & 125,4 & 0,291 & 9.1. Спирт & 9,6 & 0,036 \\
\hline 7.2. Прочие экстрагируемые & & & 9.2. Вода & 258,4 & 0,964 \\
\hline вещества & 35,3 & 0,082 & & & \\
\hline 7.3. Спирт & 9,8 & 0,023 & & & \\
\hline 7.4. Вода & 259,7 & 0,604 & & & \\
\hline & & & 10. Сухой экстракт, в т.ч.: & $\underline{160,7}$ & $\underline{1,000}$ \\
\hline & & & 10.1. Бетулин & 124,8 & 0,777 \\
\hline & & & 10.2. Прочие экстрагируемые вещества & 35,1 & 0,218 \\
\hline & & & 10.3. Вода & 0,8 & 0,005 \\
\hline & & & Потери общие & 1,5 & 1,000 \\
\hline Итого: & 430,2 & & Итого: & 430,2 & \\
\hline
\end{tabular}

Таблица 3. Материальный баланс процесса перекристаллизации экстракта

\begin{tabular}{|c|c|c|c|c|c|}
\hline \multicolumn{3}{|l|}{ Приход } & \multicolumn{3}{|l|}{ Расход } \\
\hline Компонент & Macca, $\Gamma$ & Масс. дол. & Компонент & Macca, $\Gamma$ & Масс. дол. \\
\hline 10. Сухой экстракт, в Т.ч.: & 160,7 & $\underline{1,000}$ & 12. Твердый остаток, в т.ч.: & $\underline{121,1}$ & $\underline{1,000}$ \\
\hline 10.1. Бетулин & 124,8 & 0,777 & 12.1. Бетулин & 28,4 & 0,235 \\
\hline 10.2. Прочие экстрагируемые & & & 12.2. Прочие экстрагируемые вещества & 29,4 & 0,243 \\
\hline вещества & 35,1 & 0,218 & 12.3. Углеводороды & 63,3 & 0,522 \\
\hline 10.3. Вода & 0,8 & 0,005 & & & \\
\hline 11. Углеводороды на перекри- & 2000 & 1,000 & 13. Бетулин очищенный, в т.ч.: & $\underline{122,6}$ & $\underline{1,000}$ \\
\hline сталлизацию & & & 13.1. Бетулин & 91,9 & 0,750 \\
\hline & & & 13.2. Прочие экстрагируемые вещества & 1,5 & 0,012 \\
\hline & & & 13.3. Углеводороды & 29,2 & 0,238 \\
\hline 12. Углеводороды на промывку & 300 & 1,000 & 14. Маточник, в т.ч.: & $\underline{2168,3}$ & $\underline{1,000}$ \\
\hline & & & 14.1. Бетулин & 1,9 & 0,001 \\
\hline & & & 14.2. Прочие экстрагируемые вещества & 3,4 & 0,002 \\
\hline & & & 14.3. Вода & 0,7 & 0,000 \\
\hline & & & 14.4. Углеводороды & 2162,3 & 0,997 \\
\hline & & & Потери общие & 48,7 & 1,000 \\
\hline Итого: & 2460,7 & & Итого: & 2460,7 & \\
\hline
\end{tabular}


Таблица 4. Материальный баланс процесса сушки бетулина очищенного

\begin{tabular}{|c|c|c|c|c|c|}
\hline \multicolumn{3}{|l|}{ Приход } & \multicolumn{3}{|l|}{ Расход } \\
\hline Компонент & Macca, $\Gamma$ & Масс. дол. & Компонент & Macca, $\Gamma$ & Масс. дол. \\
\hline 13. Бетулин очищенный, в т.ч.: & 122,6 & 1,000 & 15. Продукт, в т.ч.: & $\underline{93,6}$ & $\underline{1,000}$ \\
\hline 13.1. Бетулин & 91,9 & 0,750 & 15.1. Бетулин & 91,4 & 0,976 \\
\hline 13.2. Прочие экстрагируемые & & & 15.2. Прочие экстрагируемые вещества & 1,4 & 0,015 \\
\hline вещества & 1,5 & 0,012 & 15.3. Углеводороды & 0,8 & 0,009 \\
\hline 13.3. Углеводороды & 29,2 & 0,238 & & & \\
\hline & & & 16. Пары углеводородов & 27,1 & 1,000 \\
\hline & & & Потери общие & 1,9 & 1,000 \\
\hline Итого: & 122,6 & & Итого: & 122,6 & \\
\hline
\end{tabular}

Для анализа качества получаемого бетулина использовали метод ВЭЖХ. Идентификацию соединений осуществляли методом спектроскопии ЯМР. Анализы проводились по методикам, описанным нами ранее $[14,15]$.

\section{Обсуждение результатов}

Экстрагирование является одним из основных способов разделения растительного сырья на индивидуальные компоненты или их комплексы. Экстрагенты подбираются исходя из физико-химических свойств экстрагируемых соединений. Подбором соответствующего растворителя можно добиться селективности экстрагирования.

Наиболее часто применяют простые в исполнении и результативные методы: мацерация, дигерирование, перколяция, перфорация и экстрагирование. Очень часто между этими процессами нельзя провести четкой границы.

Эффективность любого вида экстракции твердого вещества жидкостью зависит, прежде всего, от его растворимости и скорости перехода из одной фазы в другую. Скорость перехода вещества из твердой фазы в раствор определяется, в основном, скоростью проникновения жидкости в твердую фазу, скоростью диффузии вещества в жидкости и скоростью удаления вещества с поверхности раздела фаз. В отличие от системы двух жидких фаз равновесие на границе твердой и жидкой фаз наступает очень медленно.

В предлагаемой технологии тонкопленочной парофазной экстракции приближение к равновесному состоянию для интенсификации процесса экстракции достигается постоянной подачей свежего растворителя на границу раздела фаз береста - экстрагент. Кроме того, достижение равновесия ускоряется посредством противотока экстрагента по высоте колонны.

Другим важным отличием разработанной технологии является то, что процесс экстракции бересты и ее последующей отпарки (удаления растворителя) осуществляется в одном аппарате, что значительно повышает пожаробезопасность производства.

Предлагаемый метод, в отличие от классических методов экстракции, например, перколяции, позволяет добиться высоких степеней извлечения целевого компонента при относительно низкой удельной загрузке спирта на один цикл, т.е. соотношение экстрагент : кора - минимальное. Это улучшает техникоэкономические показатели производства.

Удобным является использование алифатических высококипящих углеводородов для перекристаллизации бетулинсодержащих экстрактов. Ранее было показано [17], что использование для перекристаллизации таких растворителей, как низшие алифатические спирты, хлороформ, ацетон, этилацетат, дихлорметан приводит к образованию достаточно устойчивых сольватных комплексов с бетулином, что затрудняет его выделение как индивидуального соединения.

При перекристаллизации же из алифатических высококипящих углеводородов удается избежать образования сольватных комплексов бетулина. Кроме того, растворимость бетулина в углеводородных растворителях в значительной мере зависит от температуры, и использование растворителей, с помощью которых проводят процесс перекристаллизации в диапазоне температур 150-180 들 позволяет количественно перевести бетулин в жидкую фазу, а при охлаждении количественно высадить, что существенно сокращает потери бетулина в маточном растворе (1,6-1,8\%). При этом первая перекристаллизация позволяет получить продукт чистотой 84,6-95,4\%, повторная - 88,2-98,3\%. Согласно предложенной технологии, выход очищенного бетулина составляет 91,4 г на 1000 г исходной бересты. 


\section{Bbыводbl}

Предлагаемая технология получения бетулина методом парофазной тонкопленочной экстракции позволяет интенсифицировать процесс экстракции за счет проведения процесса в тонком слое на границе раздела фаз при орошении слоя бересты конденсатом экстрагента, а также за счет повышенного градиента концентраций экстрактивных веществ в системе экстрагент - береста. В результате последующей очистки путем перекристаллизации из высококипящих алифатических углеводородов получаемые образцы содержат 84,6-95,4\% бетулина. После второй перекристаллизации содержание бетулина - 88,2-98,3\%. При этом потери бетулина в маточнике составляют 1,6-1,8\%.

\section{Список литературы}

1. Долгодворова С.Я., Черняева Г.Н. Дубильные вещества коры березы // Биологические ресурсы лесов Сибири: сборник трудов Института леса и древесины СО АН СССР. Красноярск, 1980. С. 72-80.

2. Толстиков Г.А., Флехтер О.Б., Шульц Э.Э., Балтина Л.А., Толстиков А.Г. Бетулин и его производные. Химия и биологическая активность // Химия в интересах устойчивого развития. 2005. №13. С. 1-31.

3. Matsuda H., Ishikado A., Nishida N. Hepatoprotective, superoxide scavenging and antioxidative activities of aromatic constituens from the bark of Betula platyphylla var. japonica // Bioorganic \& Medicinal Chemistry Letter. 1998. Vol. 8. Pp. 2939-2944.

4. Urban M., Sarek J., Klinot J. Korinkova G., Hajduch M. Synthesis of A-Seco Derivatives of Betulinic Acid with Cytotoxic Activity // Journal of Natural Products. 2004. Vol. 67. Pp. 1100-1105.

5. Кузнецова С.А., Титова Н.М., Калачева Г.С. Зайбель И.А. Изучение состава и антиоксидантных свойств гексанового и этанольного экстрактов бересты // Вестник Красноярского государственного университета. Естественные науки. 2005. С. 113-118.

6. Pavlova N.I., Savinova O.V., Nikolaeva S.N. et. al. Antiviral activity of betulin, betulinic and betulonic acids against some enveloped and nonenveloped viruses // Foroterapia. 2003. Vol. 74. № 5. Pp. 489-492.

7. Evers, M., Poujade, C., Soler, F., Ribeill, Y., James, C., Lelièvre, Y., Gueguen, J.-C., Reisdorf, D., Morize, I., Pauwels, R., De Clercq, E., Hénin, Y., Bousseau, A., Mayaux, J.-F., Le Pecq, J.-B., Dereu, N. Betulinic Acid Derivatives: A New Class of Human Immunodeficiency Virus Type 1 Specific Inhibitors with a New Mode of Action // J. Med. Chem. 1996. Vol. 39. Pp. 1056-1068.

8. Левданский В.А., Полежаева Н.И., Кузнецов Б.Н. Экстракционная переработка коры березы без ее предварительного разделения на бересту и луб // Вестник Красноярского государственного университета. 2004. № 2. C. $68-73$.

9. Патент 2298558 (РФ). Способ получения экстрактивных веществ из бересты березы / А.А. Бакибаев, В.В. Жук, Д.М. Медведев, А.Ю. Яговкин, В.А. Яновский. 10.05.2007.

10. Патент 2206572 (РФ). Способ выделения бетулинола / М.С. Борц, Е.Г. Николаева, И.С. Лаевский. 20.06.2003.

11. Кузнецова С.А., Скворцова Г.П., Калачева Г.С., Зайбель И.А., Ханчич О.А. Изучение состава этанольного экстракта бересты и его токсико-фармакологических свойств // Химия растительного сырья. 2010. №1. C. 137-141.

12. Кузнецова С.А., Кузнецов Б.Н., Веселова О.Ф., Кукина Т.П., Скворцова Г.П., Калачева Г.С. Изучение состава гексанового экстракта бересты и его токсико-фармакологических свойств // Химия растительного сырья. 2008. №1. С. 45-49.

13. Жук В.В., Бакибаев А.А., Яновский В.А., Медведев Д.М., Яговкин А.Ю. Исследование влияния природы экстрагентов в процессе тонкопленочной парофазной экстракции на состав, степень извлечения и форму получаемых продуктов // Известия Томского политехнического университета. 2007. Т. 311. № 3. С. 99-101.

14. Патент 2463306 (РФ). Способ очистки бетулина / Яновский В.А., Андриенко О.С., Жук В.В., Бакибаев А.А., Сачков В.И. 10.10.2012.

15. Жук В.В., Яновский В.А., Яновская Е.А., Бакибаев А.А., Андриенко О.С., Шарафеев Ш.М., Сачков В.И. Перекристаллизация экстрактов бетулина из высококипящих углеводородных растворителей // Химия растительного сырья. 2012. №2. С.73-78.

16. Селянина Л.И. Выделение бетулина из отходов переработки березы экстракцией спиртом // Известия вузов. Лесной журнал. 2004. №6. С. 47-49.

17. Михайленко М.А., Шахтшнейдер Т.П., Брезгунова М.Е., Дребущак В.А., Кузнецова С.А., Болдырев В.В. Получение и исследование физико-химических свойств сольватов бетулина // Химия растительного сырья. 2010. №2. C. $63-70$.

Поступило в редакииюю 14 октября 2013 г. 
Zhuk V.V. ${ }^{{ }^{*}}$, Ianovskii V.A. ${ }^{l}$, Sambueva O.B. ${ }^{l}$, Bakibaev A.A. ${ }^{2}$ TECHNOLOGY OF THIN-FILM METHOD BETULIN VAPOR-PHASE EXTRACTION

${ }^{1}$ Siberian Physical-Technical Institute Acad. V.D. Kuznetsova Tomsk State University, Novosobornaia pl., 1, Tomsk, 634050 (Russia), e-mail: vladzhuk1980@gmail.com

${ }^{2}$ National Research Tomsk Polytechnic University, Lenina pl., 30,Tomsk, 634050 (Russia), e-mail: bakibaev@mail.ru

The article presents the technology of preparation and purification of betulin from birch bark. The preparation of betulin is carried out by the thin-film vapor-phase extraction, allowing to intensify the extraction through conducting the process in thin layer under refluxing of layer birch bark by the extractant condensate, and also due to the increased gradient of concentrations of extractives in the system of extractant - birch bark. Water-ethanol mixture is used as the extractant. Purification of obtained total extract is made by its recrystallization from high boiling aliphatic hydrocarbons or their mixtures. The developed technology allows to prepare betulin, suitable for further use in organic synthesis without additional purification. According to the proposed technology, the yield of purified betulin of purity $88,2-98,3 \%$ is $91,4 \mathrm{~g}$ per $1000 \mathrm{~g}$ of initial bark. The used birch bark can be applied for later extraction of fatty hydroxy acids from it.

Keywords: betulin, extraction, recrystallization.

\section{References}

1. Dolgodvorova S.Ia., Cherniaeva G.N. Biologicheskie resursy lesov Sibiri: Sbornik trudov Instituta lesa i drevesiny SO AN SSSR. [Forest biological resources of Siberia: Proceedings of the Institute of Forest and Wood SB RAS]. Krasnoyarsk, 1980, pp. 72-80. (in Russ.).

2. Tolstikov G.A., Flekhter O.B., Shul'ts E.E., Baltina L.A., Tolstikov A.G. Khimiia v interesakh ustoichivogo razvitiia, 2005, no. 13, pp. 1-31. (in Russ.).

3. Matsuda H., Ishikado A., Nishida N. Bioorganic \& Medicinal Chemistry Letter, 1998, vol. 8, pp. 2939-2944.

4. Urban M., Sarek J., Klinot J. Korinkova G., Hajduch M. Journal of Natural Products, 2004, vol. 67, pp. 1100-1105.

5. Kuznetsova S.A., Titova N.M., Kalacheva G.S. Zaibel' I.A. Vestnik Krasnoiarskogo gosudarstvennogo univer-siteta. Estestvennye nauki, 2005, pp. 113-118.

6. Pavlova N.I., Savinova O.V., Nikolaeva S.N. et. al. Foroterapia, 2003, vol. 74, no. 5, pp. 489-492.

7. Evers, M., Poujade, C., Soler, F., Ribeill, Y., James, C., Lelièvre, Y., Gueguen, J.-C., Reisdorf, D., Morize, I., Pauwels, R., De Clercq, E., Hénin, Y., Bousseau, A., Mayaux, J.-F., Le Pecq, J.-B., Dereu, N. J. Med. Chem., 1996, vol. 39, pp. 1056-1068.

8. Levdanskii V.A., Polezhaeva N.I., Kuznetsov B.N. Vestnik Krasnoiarskogo gosudarstvennogo universiteta, 2004, no. 2, pp. 68-73. (in Russ.).

9. Patent 2298558 (RU). 10.05.2007. (in Russ.).

10. Patent 2206572 (RU). 20.06.2003. (in Russ.).

11. Kuznetsova S.A., Skvortsova G.P., Kalacheva G.S., Zaibel' I.A., Khanchich O.A. Khimiia rastitel'nogo syr'ia, 2010 , no. 1, pp. 137-141. (in Russ.).

12. Kuznetsova S.A., Kuznetsov B.N., Veselova O.F., Kukina T.P., Skvortsova G.P., Kalacheva G.S. Khimiia rastitel'nogo syr'ia, 2008, no. 1, pp. 45-49. (in Russ.).

13. Zhuk V.V., Bakibaev A.A., Ianovskii V.A., Medvedev D.M., Iagovkin A.Iu. Izvestiia Tomskogo politekhnicheskogo universiteta, 2007, vol. 311, no. 3, pp. 99-101. (in Russ.).

14. Patent 2463306 (RU). 10.10.2012. (in Russ.).

15. Zhuk V.V., Ianovskii V.A., Ianovskaia E.A., Bakibaev A.A., Andrienko O.S., Sharafeev Sh.M., Sachkov V.I. Khimiia rastitel'nogo syr'ia, 2012, no. 2, pp. 73-78. (in Russ.).

16. Selianina L.I. Izvestiia vuzov. Lesnoi zhurnal, 2004, no. 6, pp. 47-49. (in Russ.).

17. Mikhailenko M.A., Shakhtshneider T.P., Brezgunova M.E., Drebushchak V.A., Kuznetsova S.A., Boldyrev V.V. Khimiia rastitel'nogo syr'ia, 2010, no. 2, pp. 63-70. (in Russ.). 
